


\section{DISCLAIMER}

This report was prepared as an account of work sponsored by an agency of the United States Government. Neither the United States Government nor any agency Thereof, nor any of their employees, makes any warranty, express or implied, or assumes any legal liability or responsibility for the accuracy, completeness, or usefulness of any information, apparatus, product, or process disclosed, or represents that its use would not infringe privately owned rights. Reference herein to any specific commercial product, process, or service by trade name, trademark, manufacturer, or otherwise does not necessarily constitute or imply its endorsement, recommendation, or favoring by the United States Government or any agency thereof. The views and opinions of authors expressed herein do not necessarily state or reflect those of the United States Government or any agency thereof. 


\section{DISCLAIMER}

Portions of this document may be illegible in electronic image products. Images are produced from the best available original document. 


\section{LEGAL NOTICE}

This report was prepared as an account of work sponsored by the United States Government. Neither the United States nor the United States Atomic Energy Commission, nor any of their employees, nor any of their contractors, subcontractors, or their employees, makes any warranty, expressed or implied, or assumes any legal liability or responsibility for the accuracy, completeness or usefulness of any information, apparatus, product or process disclosed, or represents that its use would not infringe privately owned rights.

Printed in the United States of America Available from the

National Technical Information Service

U. S. Department of Commerce Springfielrl, Virginia 22151

Price: Printed Copy $\$ 4.00$ Microfiche $\$ 1.45$ 


\title{
CRITICALITY DRAIN PERFORMANCE STUDY
}

\author{
George D. Lehmkuhl
}

Chemistry Research and Development PROCESS CHEMISTRY

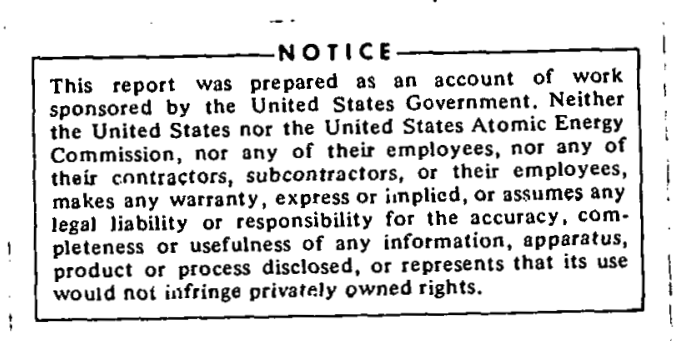

\section{DOW CHEMICAL U.S.A. ROCKY FLATS DIVISION P. O. BOX 888 \\ GOLDEN, COLORADO 80401}

Prepared under Contract AT(29-1)-1106

for the

Albuquerque Operations Office

U. S. Atomic Energy Commission 
RFP-2222 


\section{CONTENTS}

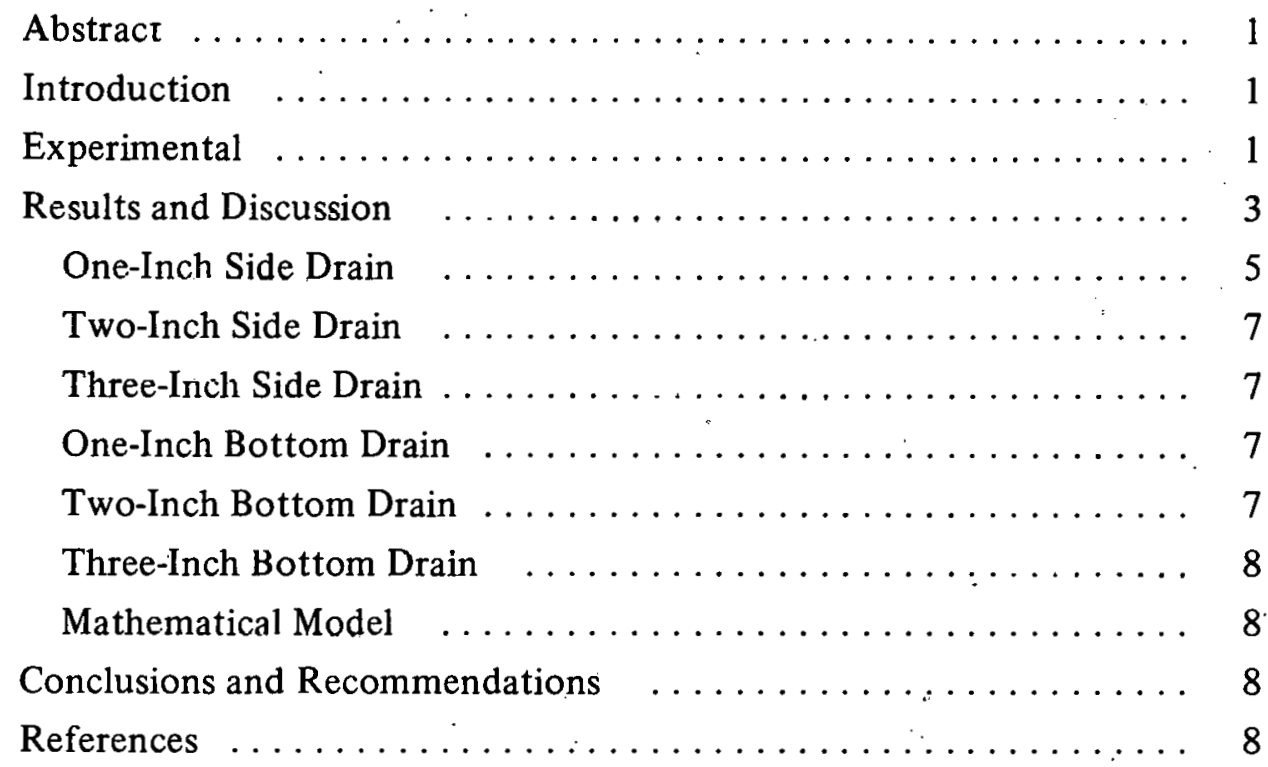




\section{A C K N O W L E D G M N T S}

R. L. Smith and D. E. Auten were of considerable help in setting up the equipment and taking experimental data. J. R. Wolf aided in making equipment drawings. J. W. Beltz aided in the initial design of equipment and experiments. The work performed by these people is appreciated. 


\title{
CRITICALITY DRAIN PERFORMANCE STUDY
}

\author{
George D. Lehmkuhl
}

\begin{abstract}
A study was made to determine the liquid head necessary to sustain various liquid flow rates in glovebox criticality drains. Liquid head is the height of liquid above a drain outlet opening in a glovebox. One bottom and side drain each for 1-, 2-, and 3-inch diameter pipe were simulated in a glovebox model. The 1 -inch side and bottom drains and the 2- and 3-inch side drains require higher liquid heads than the other 2 drains. A 2-inch side drain, for example, requires a 1.7-inch head to flow $12 \mathrm{gpm}$ while a 2 -inch bottom drain requires only a 0.7 -inch head. These test data can be used in the design of gloveboxes and for evaluation of existing glovebox criticality drains. Probable leak rates into gloveboxes can be used with these test data to predict probable liquid levels in the gloveboxes.
\end{abstract}

\section{INTRODUCTION}

Critical mass incidents; i.e., accidental, uncontrolled fission reactions, are prevented by controlling the quantity of fissionable material in a particular location and controlling the geometry of the containment vessel. The quantity of fissionable material allowed and the geometry of the container are based on a number of considerations, among them the neutron reflection properties of the immediate environment. Water and similar hydrogenous media reflect neutrons into a potentially fissionable mass, thereby lowering the amount of fissionable material required to achieve a critical mass.

Relatively large volumes of solutions of fissionable materials may be maintained in small diameter, properly spaced cylinders, in flat slab tanks, or in Raschig ring-filled tanks so that the neutron population per unit volume is lower than that required for a self-sustaining fission reaction. Gloveboxes containing more than a few grams of plutonium are normally required to have a means of controlling the level of water or solution of fissionable material that might accidentally accumulate. The accidental accumulation might result from such events as a process solution line break, a cooling water line break, or a window rupture during a time when room water sprinklers are activated.

The most frequently used liquid-level control at the Rocky Flats Division is a raised drain outlet in the glovebox floor (Figure 1). The drain has a liquid seal (drain pot) to prevent movement of air through the drain. When the liquid level in a glovebox reaches the height of the drain outlet opening, the liquid will begin to flow through the pipe and out of the box through the drain. The rate of flow from the criticality drain is related to the height of liquid in the glovebox above the drain outlet opening. This height is called the liquid head. Higher flow rates require larger liquid heads.

To prevent a nuclear criticality, the liquid in a glovebox must not rise above a specified level. Therefore, it is necessary to know the liquid heads required to produce various drain flow rates from the glovebox. The maximum permissible liquid level, the maximum liquid leak flow rate into the glovebox, and the drain outlet flow rate can then be used to design the proper criticality drain for the glovebox.

This study was made to determine the liquid head necessary to sustain various flow rates in criticality drains. These drains were simulated in a glovebox model and included one bottom and side drain each for 1-, 2-, and 3-inch diameter pipes.

\section{EXPERIMENTAL}

The test apparatus consisted of a rectangular tank with 6 test drain openings as shown in Figure 1. The tank was constructed of stainless steel with a plastic front to allow observation of the liquid 


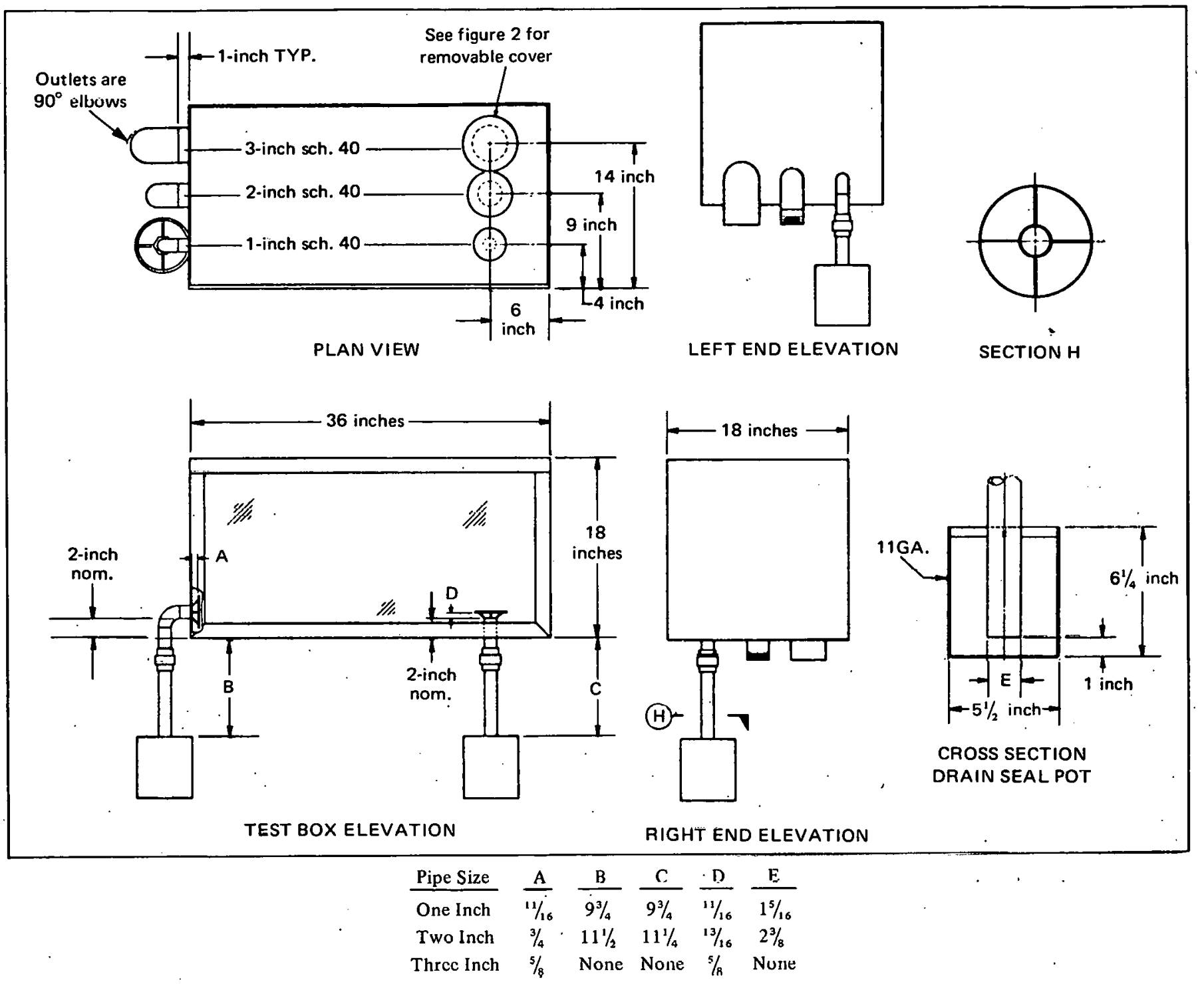

FIGURE 1. Test Box and Seal Pot.

height and flow. The drain pipes were of Schedule 40 stainless steel pipe. Rulers were placed at various points in the box to measure liquid depth.

Drain seal pots (see Figure 1) for the 1- and 2-inch drains could be coupled to the drain pipes by screwed couplings. 'l'he 1-, 2-, and 3-inch drain covers (Figures 1 and 2 ) were removable. Tests were made with and without the drain pots and drain covers.

A centrifugal pump supplied water to the test box through a rotameter and flexible tubing. All drains, except the drain to be tested, were stoppered.
The water was introduced in to the opposite end of the box from the drain to be used. A baffle plate was placed near the inlet hose to reduce wave action in the box at higher inlet flow rates.

The inlet flow rate was set on the calibrated rotameter and after a steady state liquid level was reached, a level reading was taken. When oscillatory discharge flow occurred, the minimum and maximum depths were recorded. The liquid depth was nearly uniform in the central portions of the box $( \pm 1 / 32$ inch on the rulers used for these measurements). The liquid head driving the flow out the drains was calculated from the liquid height 


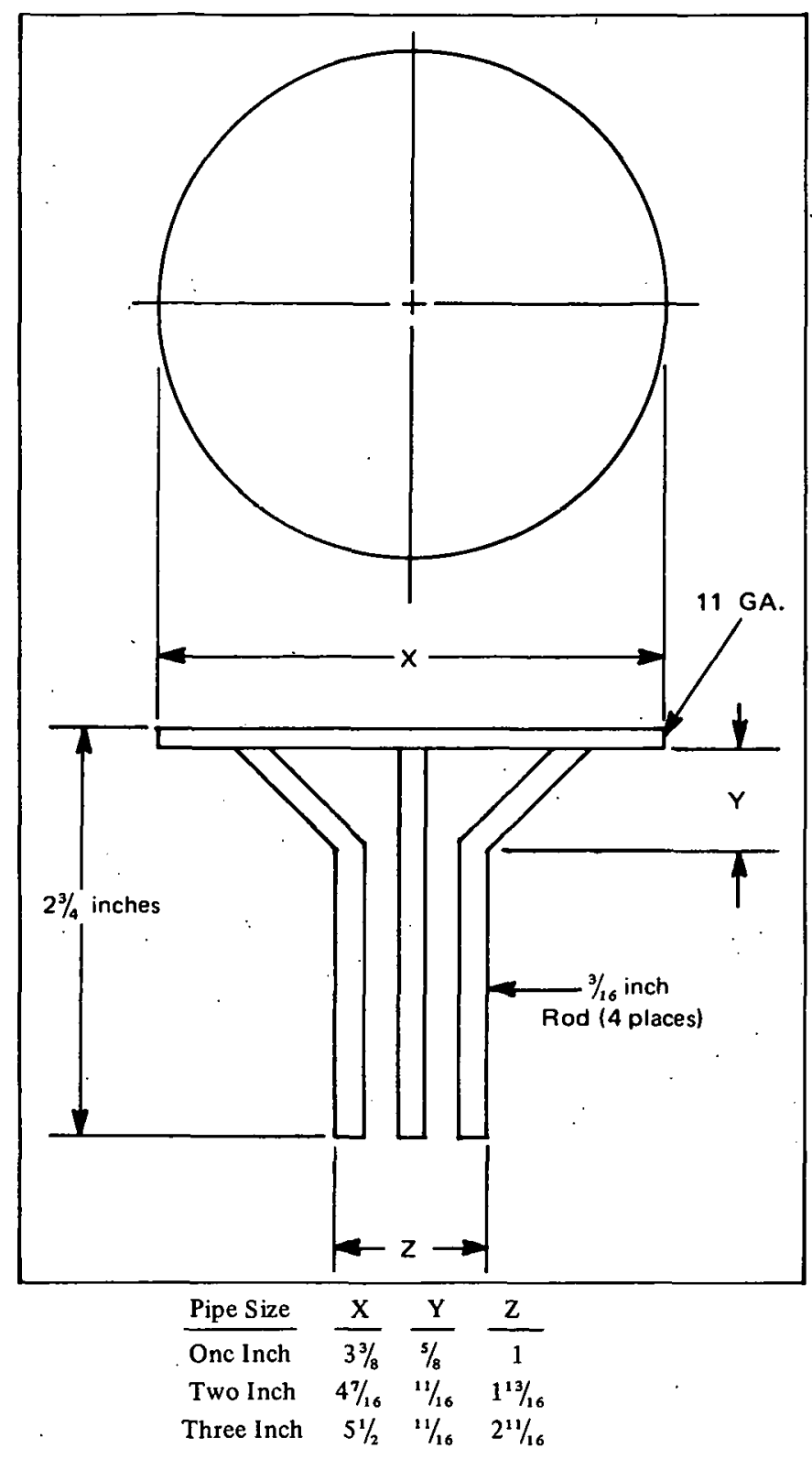

FIGURE 2. Removable Cover.

measured in the central portion of the box minus the height of the drain opening. The height of the drain opening for side drains was considered to be the lowest point of the pipe opening.

\section{RESULTS AND DISCUSSION}

The maximum flow rates for each type of drain are compared in Figure 3. The flows in a 1-inch side drain are compared in Figure 4; flows in a 2-inch side drain, 1-inch bottom drain, and 2-inch bottom drain are compared in Figures 5, 6, and 7, respectively. In each case, flow measurements were taken for (1) the criticality drain with a seal pot and drain cover (see Figures 1 and 2), (2) the drain with a seal pot but without a cover, and (3) the drain without a seal pot or cover. Figure 8 compares bottom drain flows with flows calculated from a mathematical model. The equation used in Figure 8 is discussed in the section entitled "Mathematical Model."

It is possible that materials could be carried to a drain opening by flowing liquid in the glovebox. Drain covers to help prevent clogging are provided on most drains presently in use: Some of these covers hinder the flow (especially the perforated plates presently used on some drains). The type of cover shown in Figure 2 did not appreciably hinder the flow. In some cases, it helped stabilize the flow. Several tests were made with plastic and paper trash in the glovebox, but in no case did the trash clog a drain. At the flow rates tested (below $16 \mathrm{gpm}$ ), the circulation patterns in the glovebox kept trash away from the drain openings, but this does not ensure prevention of trash being carried to the drain opening or that trash will not be inadvertently placed over a drain opening. It would be wise to use nonrestricting drain covers and practice good glovebox housekeeping.

Many factors such as drain opening, use of drain covers, drain pipe length, and seal pot design will affect drain flow; therefore, any change from tested designs should be examined closely for additional flow resistances.

The test glovebox was open topped and at atmospheric pressure whereas actual gloveboxes operate at about one-inch water negative pressure with respect to the atmosphere. The effect of this glovebox vacuum on drain flow rates should be negligible. When a drain is not running full (which should be the case if drains are properly sized), the major resistance to flow is at the pipe inlet in the box. The 1 -inch water vacuum will only cause the water level at the bottom of the drain pipe, near the drain pot, to rise 1 inch in the pipe (Figure 9). 
RFP-2222

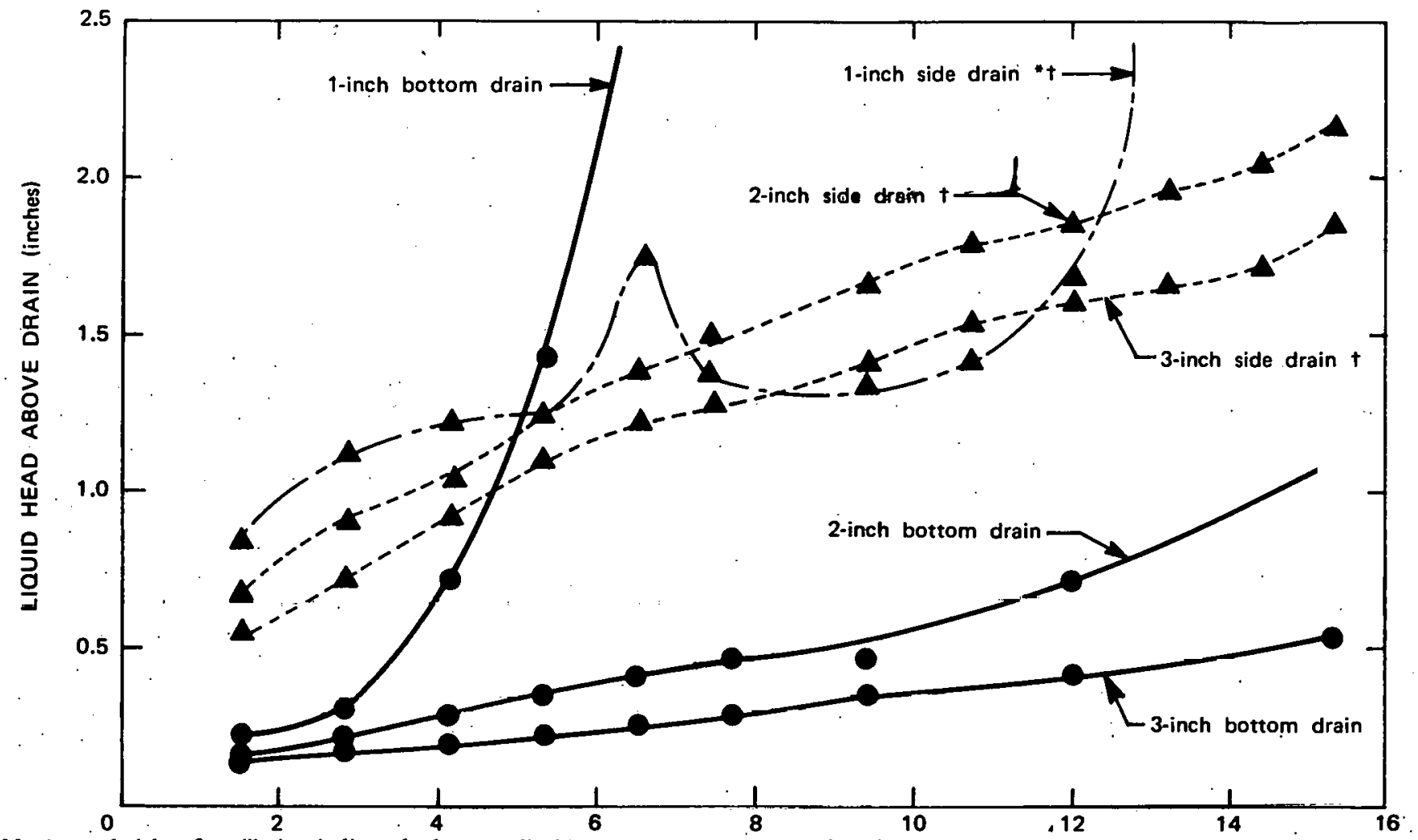

* Maximum height of oscillation indicated where applicable.

$\dagger$ Measured from bottom of hole.

FIGURE 3. Comparison of Drains Without Pot or Cover.

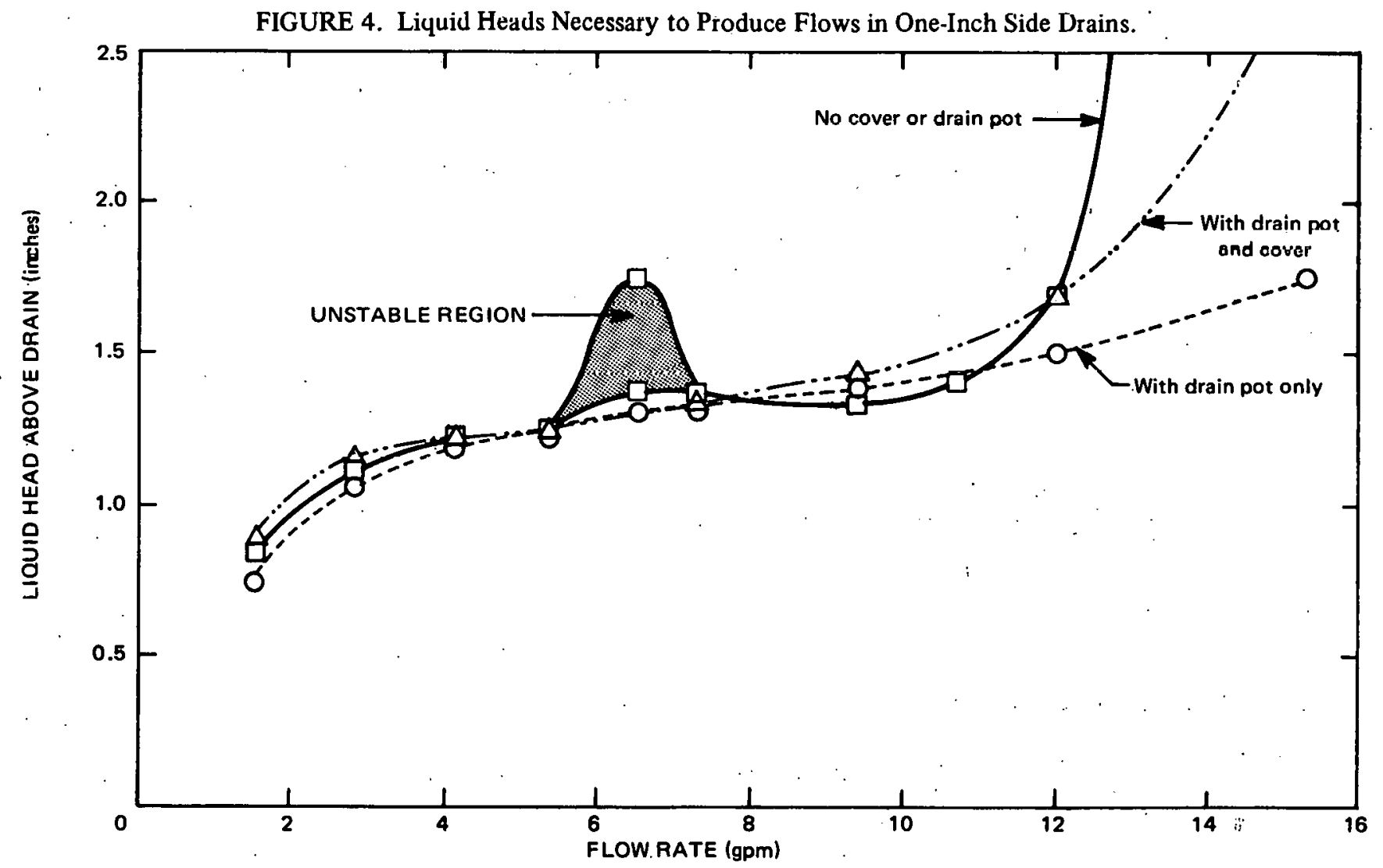


The tube length of a normal glovebox drain is about two feet. Consequently, there is a 24 -inch, liquid head driving force for the flow out of the drain pot if a drain runs full. The one-inch vacuum would reduce this driving force by only $4 \%$. This should have negligible effect on the height of water in the glovebox.

\section{One-Inch Side Drain}

The flows in the 1-inch side drain are shown in Figure 4. At low flow rates, the three cases studied needed approximately the same liquid-head levels for given flows. At higher flows (above 11 gpm), the drain began to run full and the drain cover and seal pot began to have an effect on vortex formation and flow rate. At flow rates above $4 \mathrm{gpm}$ the drain pot overflow. was not uniform and the pot would blurp periodically (with a period of 1 to 10 seconds between blurps). This probably resulted from entrainment of air by the drain vortex. Surface waves were not observed in the test glovebox.

A region of instability occurred near $6 \mathrm{gpm}$ for the drain without pot or cover. Instabilities also occurred in the test range for 1 -inch bottom drains. These regions are present because two types of vortex flow occur. When the low flow rate condition occurs, the level rises in the glovebox because the inflow is greater than the drain rate. Before the increase in liquid head can produce a drain flow to match inlet flow, a flow transition occurs. The new vortex flow is at a faster rate than the inlet flow; thus, the level begins to drop. The new, more rapid flow condition drains the liquid until the rapid flow cannot be sustained, at which time the low flow condition again appears and the level begins to rise. The flow continues in this oscillatory cycle. Below the unstable region, the low flow condition is sufficient to drain at the inlet rate and the liquid in the box reaches a stable level. Above the unstable region, the inlet rate is

FIGURE 5. Liquid Heads Necessary to Produce Flows in Two-Inch Side Drains.

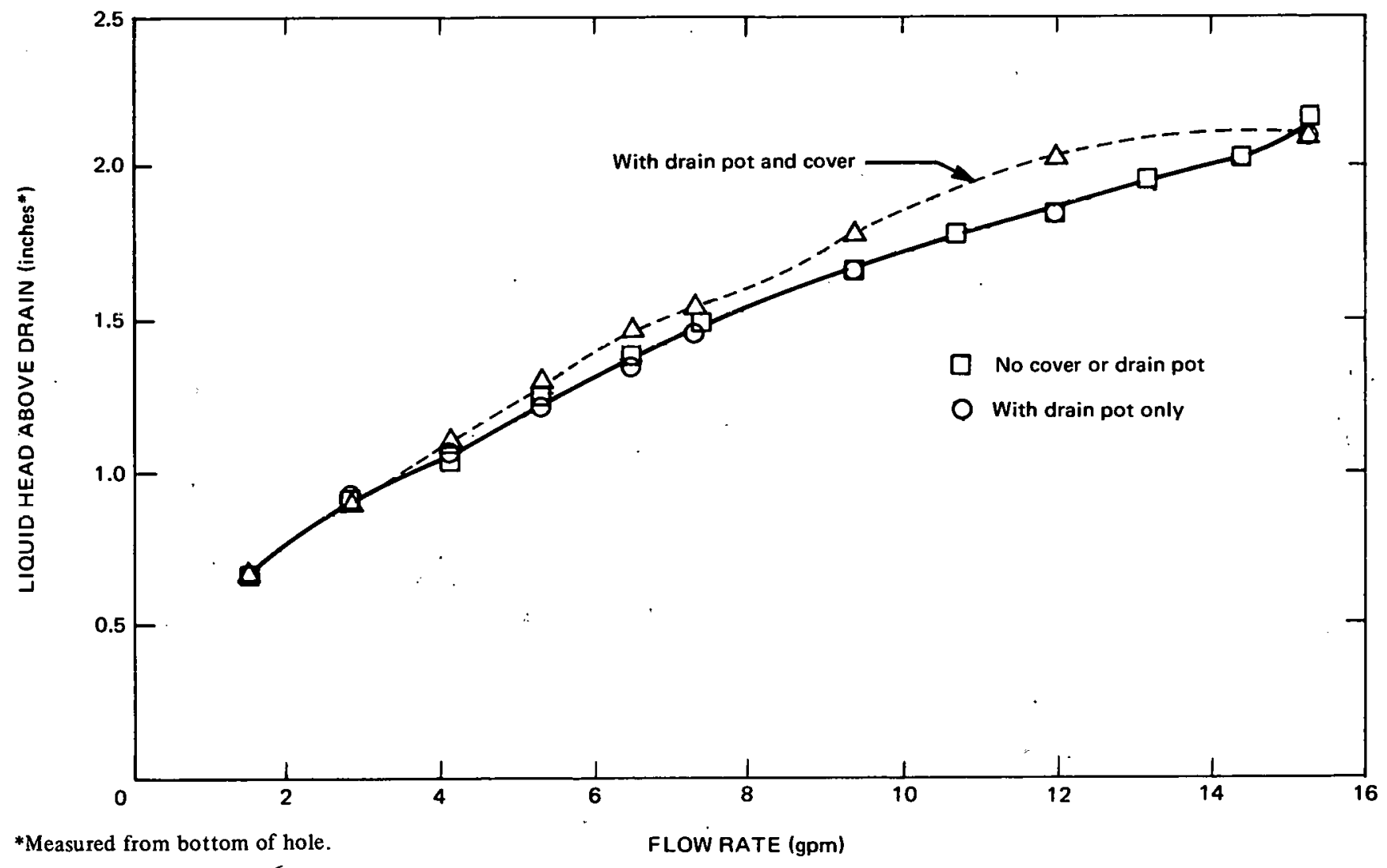


RFP-2222

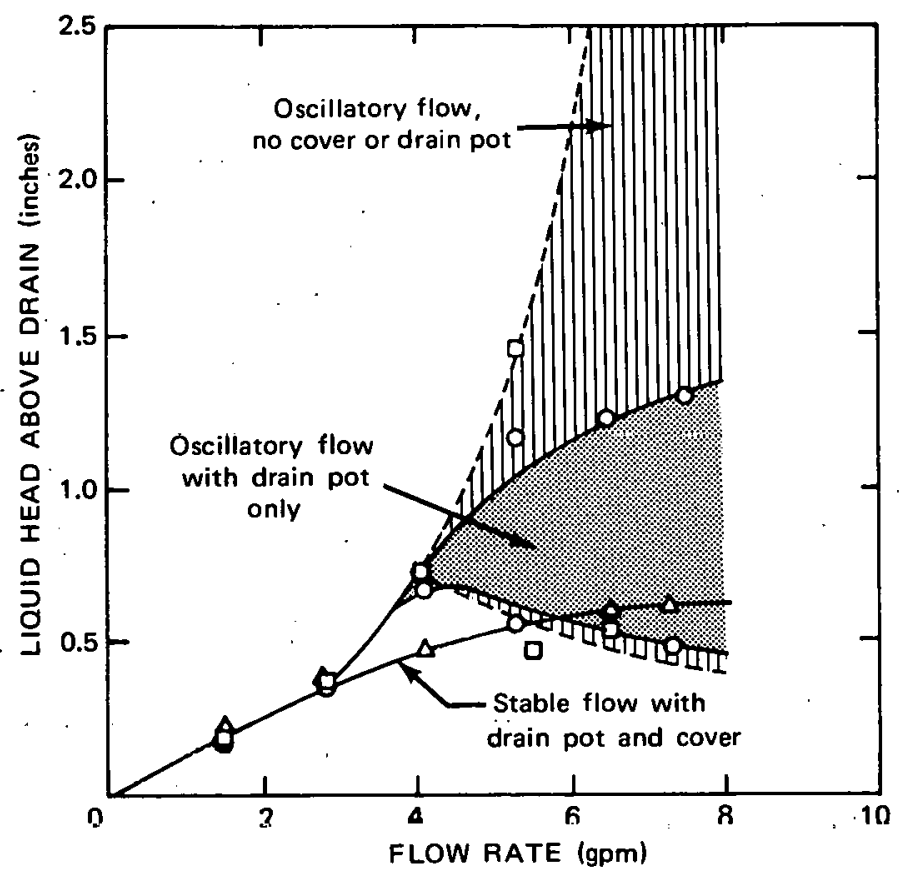

FIGURE 6. Liquid Heads Necessary to

Produce Flows in One-Inch Bottom Drains.

FIGURE 7. Liquid Heads Necessary to Produce Flows in Two-Inch Bottom Drains.

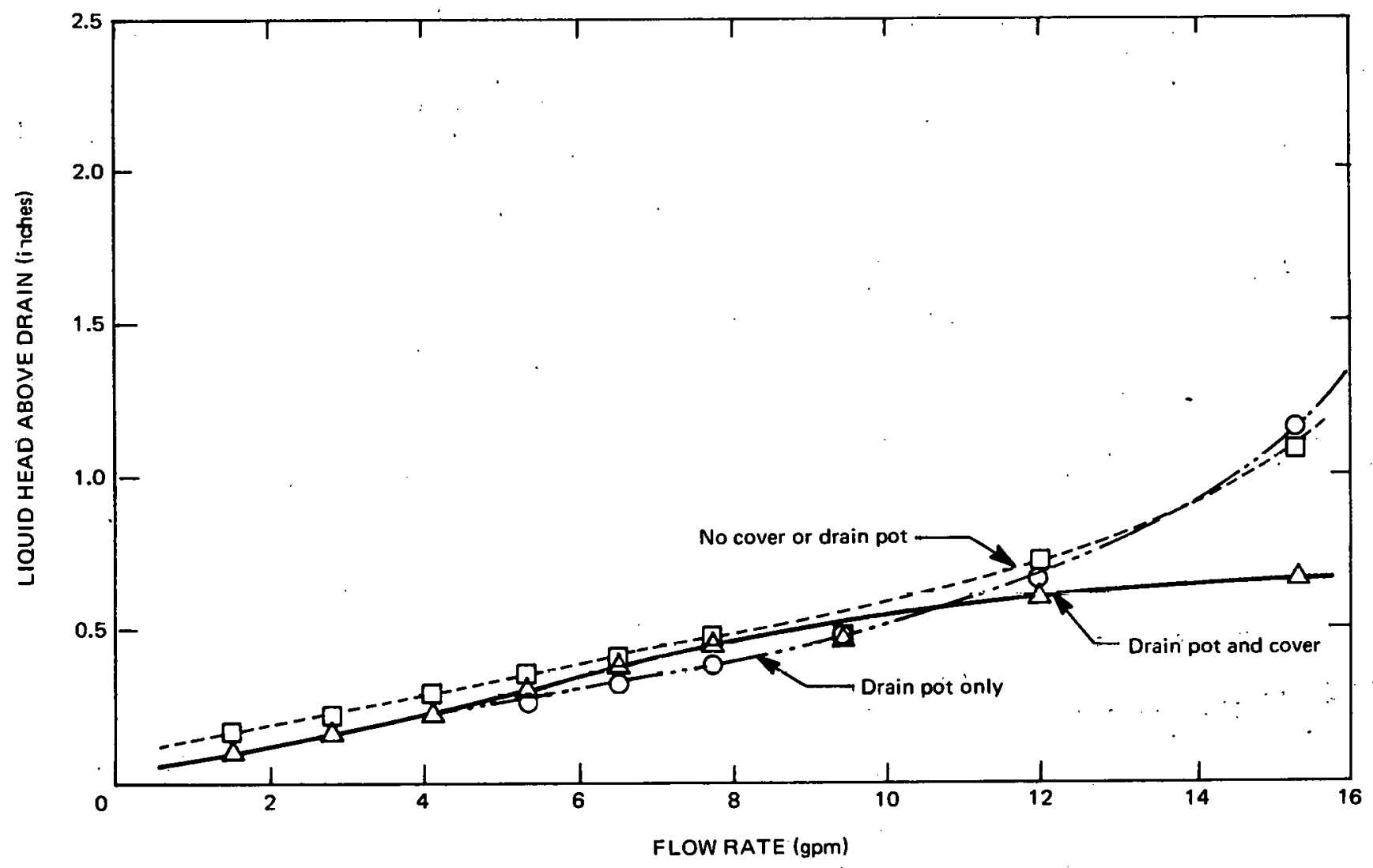


rapid enough to sustain a liquid head that will support the faster rate condition. The flow does not drop back into the low flow condition so a stable level is reached.

Since there is little flow area at low liquid levels, the liquid level rises rapidly as flow rate increases. Vortex flow begins at low flow rates.

\section{Two-Inch Side Drain}

Test results for the 2-inch side drain are shown in Figure 5. No unstable flow region was encountered in the test range. Surface waves were small, being less than $\pm 1 / 8$ inch at the highest flow rates.

The glovebox level increased rapidly as inlet flow was increased; again because of the small flow area available for flow at low liquid levels.

\section{Three-Inch Side Drain}

Tests were made only for the drain with no pot or cover since it was assumed neither the pot nor cover would have an effect on this large pipe at flows below $16 \mathrm{gpm}$. Spot tests with a drain cover showed no change from flow with no cover. Results are shown in Figure 3.

\section{One-Inch Bottom Drain}

The liquid-head. levels for various flow rates through the 1 -inch bottom drain are shown in Figure 6. The liquid level rises rapidly because of the small area available for flow and because a vortex flow condition begins at low flow rates. The unstable flow regions are caused by conditions as discussed for the 1-inch-side drain. The effects of the pot and cover alter the flow patterns enough to prevent an unstable region as shown in Figure 6. Blurping and bubbling in the drain pot were also observed as discussed for the 1 -inch side drain.

\section{Two-Inch Bottom Drain}

Test results for the 2 -inch bottom drain are shown in Figure 7. The effects of drain cover and seal

FIGURE 8. Comparison of Model and Experimental Data.

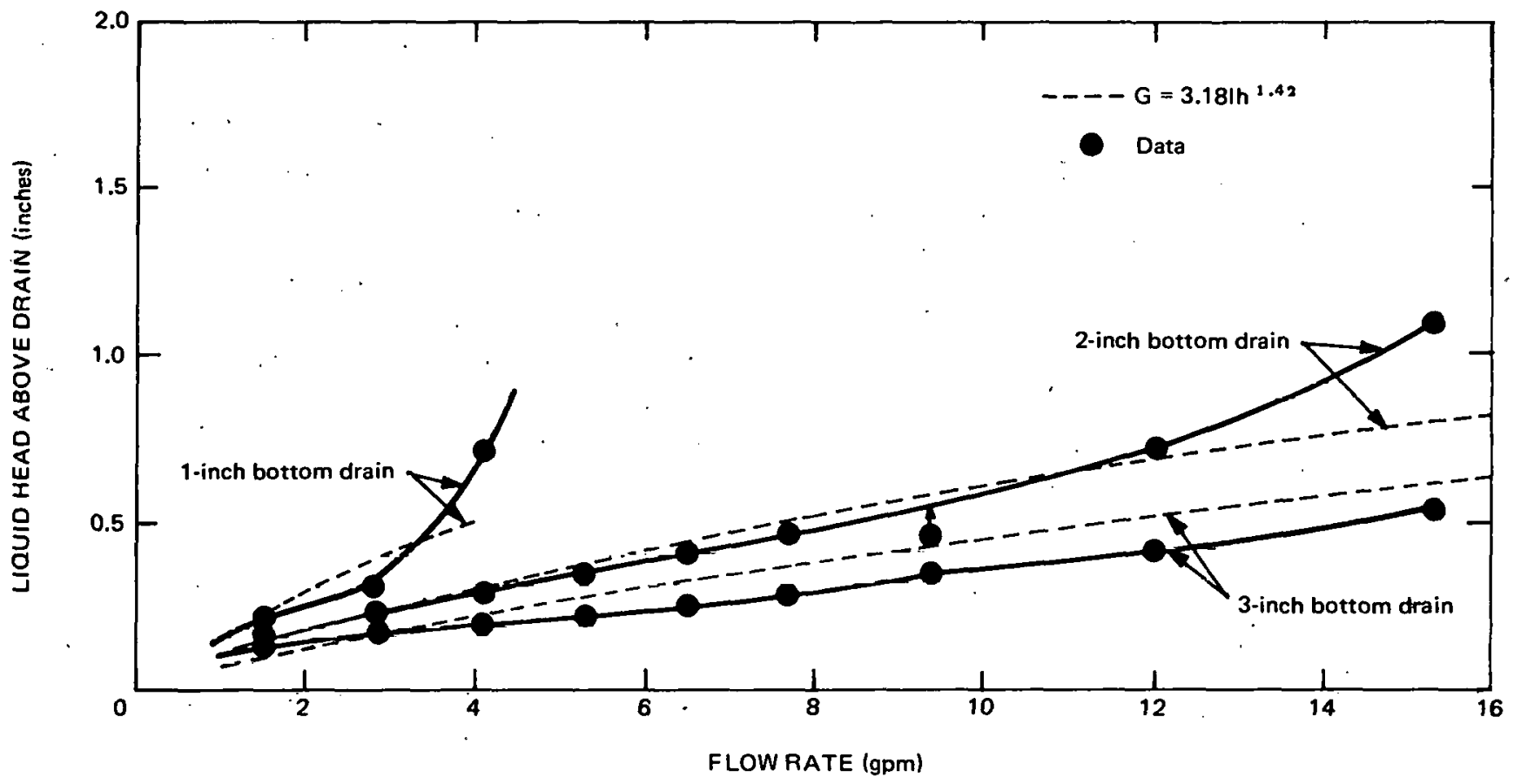


pot are insignificant below $12 \mathrm{gpm}$. Contrary to intuition about drain covers and pots causing increased flow resistance, the flow actually changed so as to decrease the liquid head when the cover and pot were added. Surface waves were less than $\pm 1 / 16$ inch.

\section{Three-Inch Bottom Drain}

Tests were conducted for only the drain with no pot or cover since it was assumed there would be no effect on flow in this large pipe below $16 \mathrm{gpm}$. Spot tests with a drain cover showed no change from flow with no cover. Results are shown in Figure 3.

\section{Mathematical Model}

At the lower flow rates, the bottom drains can be modeled by the following mathematical equations as suggested in The Chemical Engineers Handbook: ${ }^{1}$

$$
\mathrm{G}=\mathrm{K}_{1} \mathrm{lh}^{1.5} \text { or } \mathrm{K}_{2} \operatorname{lh}^{1.42}
$$

Where

$$
\begin{aligned}
& \mathrm{G}=\text { flow rate in gallons per minute } \\
& \mathrm{h}=\text { liquid head above pipe top in inches }
\end{aligned}
$$

FIGURE 9. Flow Pattern of Liquid in Criticality Drain When Draining at Low Flow Rates.

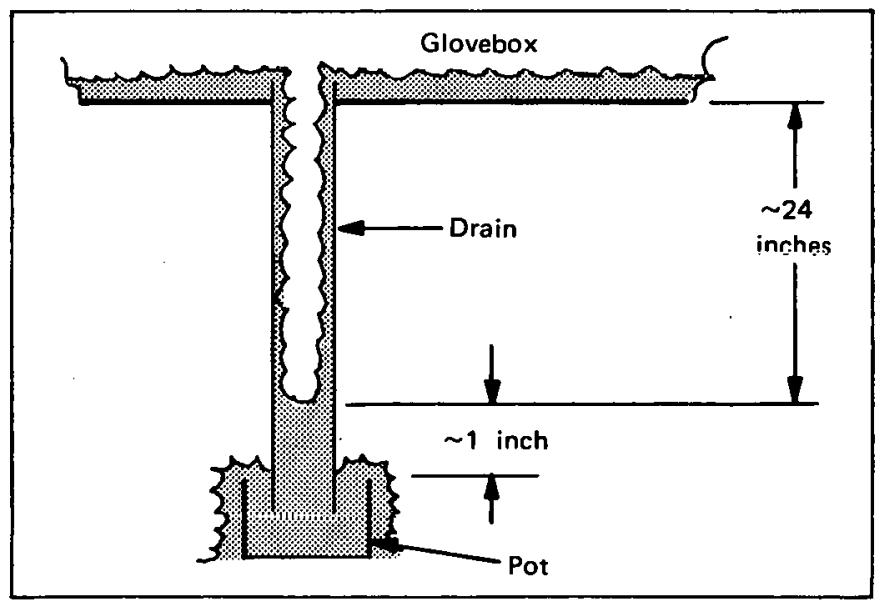

$\mathrm{K}_{1}, \mathrm{~K}_{2}=$ equation constants depending on the system (values are near 3.0 for these drains)

$$
\begin{aligned}
& 1=\text { length of wier in inches }=\text { perimeter of } \\
& \text { pipe opening }=\pi d \text { where } d=\text { the } \\
& \text { pipe diameter }
\end{aligned}
$$

Experimental data are compared in Figure 8 with the equation $\mathrm{G}=3.18 \mathrm{lh}^{1.42}$. The equation $\mathrm{G}=\mathrm{K}_{1} \mathrm{lh}^{1.5}$ also approximates the data well if $\mathrm{K}_{1}$ is chosen properly.

These equations are valid only for liquid heads that are small compared to the pipe diameter. Thus, the equation in Figure 8 is good only to about $3 \mathrm{gpm}$ for 1 -inch drains and $11 \mathrm{gpm}$ for 2-inch drains.

\section{CONCLUSIONS AND RECOMMENDATIONS}

Figures 3 through 8 can be used to estimate proper drain heights in gloveboxes. First, the maximum probable leak rate into the box must be determined. Then the liquid head, for the type of drain used and estimated flow rate, can be determined from the figures. This liquid head must then be subtracted from the maximum allowable liquid level in the glovebox to give the drain height to use in the glovebox.

In general, it is suggested that side drains not be used and that bottom drains should be 2 inches or greater in diameter. This is suggested because the side drains and the 1 -inch bottom drain will handle only low flows.

Gloveboxes should be kept clear of unneeded materials to prevent clogging of drain openings. Drain covers to help prevent clogging should be constructed so as not to hinder flow. The drain covers tested (see Figure 2) were satisfactory.

\section{REFERENCES}

1. Chemical Engineers' Handbook. 3rd Edition. Page 106. J. H. Perry, Editor. McGraw-Hill, New York. 1950. 